\title{
The syndrome of inappropriate antidiuretic hormone: prevalence, causes and consequences
}

\author{
M J Hannon and C J Thompson \\ Academic Department of Endocrinology, Beaumont Hospital and RCSI Medical School, Beaumont Road, Dublin 9, Ireland \\ (Correspondence should be addressed to C J Thompson; Email: christhompson@beaumont.ie)
}

\begin{abstract}
Hyponatraemia is the commonest electrolyte abnormality found in hospital inpatients, and is associated with a greatly increased morbidity and mortality. The syndrome of inappropriate antidiuretic hormone (SIADH) is the most frequent cause of hyponatraemia in hospital inpatients. SIADH is the clinical and biochemical manifestation of a wide range of disease processes, and every case warrants investigation of the underlying cause. In this review, we will examine the prevalence, pathophysiology, clinical characteristics and clinical consequences of hyponatraemia due to SIADH.
\end{abstract}

European Journal of Endocrinology 162 S5-S12

\section{Introduction}

Hyponatraemia is by far the most common electrolyte imbalance found in hospital inpatients (1), and severe hyponatraemia has been detected in $1 \%$ of hospital inpatients, with higher prevalence rates in the elderly (2). This is a clinically significant statistic, given that patients with symptomatic hyponatraemia have a vastly increased mortality when compared with normonatraemic controls (3). Hyponatraemia has many different pathophysiological causes, each of which needs to be managed differently, making accurate diagnosis essential to enable the commencement of therapy to reduce morbidity and mortality. The most common cause of hyponatraemia in hospital inpatients is syndrome of inappropriate antidiuretic (SIADH), which has a wide range of causes. In this review, we will discuss the prevalence, symptoms, signs and consequences of hyponatraemia due to SIADH.

\section{Prevalence of hyponatraemia}

Hyponatraemia is relatively common in ambulatory patients. A Belgian study reported that the prevalence of mild hyponatraemia $(<135 \mathrm{mmol} / \mathrm{l})$ was $4 \%$ in a randomly selected control group of healthy elderly patients (4), whereas the population-based Copenhagen Holter study showed a higher prevalence of $11 \%$, using a slightly higher cut-off of $137 \mathrm{mmol} / \mathrm{l}$ (5). However, the

This paper forms part of a supplementary issue of European Journal of Endocrinology. Otsuka Pharmaceutical Europe Ltd. has supported the publication of this supplement. incidence of new hyponatraemia in hospitalised patients is significantly higher. A large study of 7965 patients with pneumonia showed that $8 \%$ developed hyponatraemia during the course of hospital admission (6). Our own data show that $56 \%$ of the patients admitted with subarachnoid haemorrhage develop hyponatraemia, with 20\% developing clinically significant drops in plasma sodium concentration to $<125 \mathrm{mmol} / \mathrm{l}$ (7). Significant rates of hyponatraemia of between 10 and $20 \%$ also occurred in patients admitted to neurosurgical units with intracranial tumours and haematomas, and in patients undergoing pituitary surgery (8).

The almost universal finding in all cross-sectional studies of patients with hyponatraemia is the increased mortality in patients with low plasma sodium concentrations. Gill's study of hospitalised patients with plasma sodium concentration $<125 \mathrm{mmol} / \mathrm{l}$ showed an overall mortality of $28 \%$, which is significantly higher than that in eunatraemic controls (9\%) (9). However, this study also showed a clear gradation of risk of death according to the severity of hyponatraemia, with mortality of $50 \%$ in patients with plasma sodium concentrations $<115 \mathrm{mmol} /$ l. Clayton's study of patients with severe hyponatraemia $(<125 \mathrm{mmol} / \mathrm{l})$ showed that the excess mortality in this group extends beyond the time frame of hospital admission, with a mortality of $20 \%$ in hospital and $45 \%$ within 6 months of follow-up (10). The high mortality in this study was attributed to the mortality associated with the illnesses which precipitated hyponatraemia, such as cardiac failure, liver disease and small cell carcinoma of the lung. However, a role for hyponatraemia itself was suggested by a Dutch paper, which reported higher mortality rates in hyponatraemic patients who did not 
receive specific treatment for hyponatraemia compared with those who did (37 vs 13\%) (11). These data strongly suggest that hyponatraemia should not be therapeutically ignored, even if the underlying disease process is serious.

Interestingly, published data obtained from cohorts of patients with milder hyponatraemia ( <137 mmol/l) suggest that excess mortality is not confined to patients with plasma sodium concentration $<125 \mathrm{mmol} / \mathrm{l}$. Patients with mild hyponatraemia in the community (4) and with pneumonia (6), and those in intensive care (12) have all been shown to have excess mortality compared with patients with normal plasma sodium concentrations. One of the most comprehensive studies of mortality and hyponatraemia is a recently published prospective cohort study of 98411 patients hospitalised at two Boston teaching hospitals between 2000 and 2003 (13). The authors documented hyponatraemia $(<135 \mathrm{mmol} / \mathrm{l})$ in $14.5 \%$ of the patients on admission, and they were able to demonstrate that hyponatraemia increased mortality at 1 and 5 years. The risk of death was apparent even in those with mild hyponatraemia (130-134 mmol/l, hazard ratio 1.38). The large study population lent considerable power to the statistical evaluation, and the data provided conclusive evidence that mild hyponatraemia is potentially more sinister than previously considered. Data from these recent publications have re-opened the debate about the potential deleterious effects of mild hyponatraemia, which has traditionally been regarded as being asymptomatic and which does not warrant therapeutic intervention.

The data from papers cited so far have derived from generic studies of hyponatraemia, rather than from those specifically devoted to SIADH, so the relevance and implication for SIADH are assumed rather than proven. Some studies undoubtedly described a majority of patients with $\operatorname{SIADH}(7,10)$, but as many were retrospective, classical diagnostic criteria had not been applied, and the number with true SIADH was ill defined. In all studies of hyponatraemia, a significant number also have multifactorial hyponatraemia. What is clear from the prevalence data is that hyponatraemia is common, the commonest cause of hyponatraemia is SIADH and hyponatraemia due to all causes increases mortality.

\section{Hyponatraemia due to SIADH}

The first step in the diagnosis of SIADH is to differentiate it from other causes of hyponatraemia. There are a number of classifications of the pathogenesis of hyponatraemia. Some authorities have suggested a classification based on whether hyponatraemia is dilutional, depletional or redistributional in nature (14). This method has the merit of dividing hyponatraemia on pathophysiological criteria. In routine clinical practice, we have adopted a pragmatic approach to hyponatraemia, in which classification of causation is based on clinical and biochemical estimation of extracellular volume status. This divides hyponatraemia into hypovolaemic, euvolaemic and hypervolaemic aetiologies (see Table 1). The advantage in our experience is that this classification is easily understood by practitioners who are not experts in hyponatraemia. Although the clinical featues of the three categories are quite distinct, in practice, it can be difficult to distinguish mild hypovolaemia from euvolaemia. As can be seen in Table 1, the causes of hyponatraemia are quite diverse, and so, accurate diagnosis is essential to enable correct management. Hypovolaemic hyponatraemia can be difficult to diagnose, as serum urea may be low in hypovolaemic elderly patients and urinary sodium may be low in SIADH due to anorexia. In these cases, an isotonic saline infusion can be helpful. It has been shown that patients diagnosed with SIADH whose urinary osmolality is $<500 \mathrm{mosmol} / \mathrm{kg}$ raise their plasma sodium in response to isotonic saline infusion (15).

Euvolaemic hyponatraemia is the commonest cause of hyponatraemia in hospitalised patients. Although experimental models of SIADH show that blood volume is slightly expanded in SIADH (16), with suppression of

Table 1 Causes of hyponatraemia.

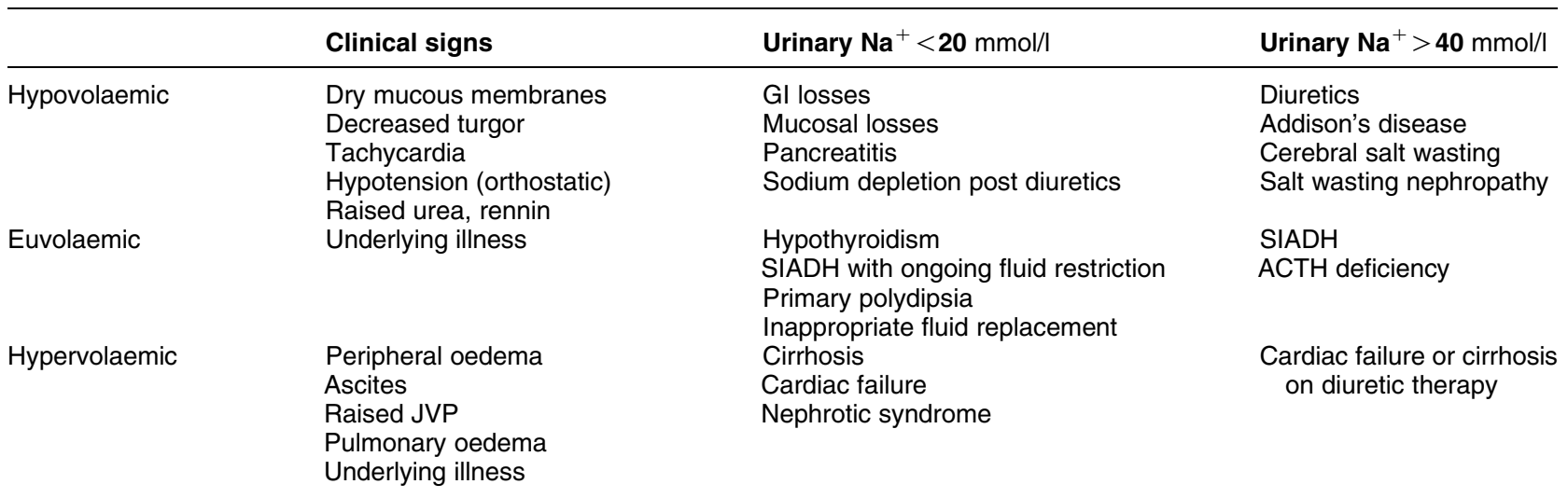

JVP, jugular venous pressure. 
plasma renin and elevation of plasma natriuretic peptides, the expanded extracellular volume is not detectable clinically and does not cause oedema. SIADH is therefore classified as euvolaemic hyponatraemia. SIADH needs to be distinguished from other causes of euvolaemic hyponatraemia, such as inappropriate hypotonic fluid replacement, particularly in patients following surgery. Hyponatraemia has also been reported to occur as a direct result of surgical procedures; for example, bladder irrigation with hypotonic solutions during transurethral resection of the prostate gland can lead to direct absorption of water from the bladder, producing euvolaemic dilutional hyponatraemia $(17,18)$. Euvolaemic hyponatraemia may also occur due to inappropriate fluid replacement after exercise (19) or diarrhoeal illness.

An important cause of euvolaemic hyponatraemia, which must be excluded before the diagnosis of SIADH can be made, is ACTH deficiency. In contrast to Addison's disease, which is characterised by both glucocorticoid and aldosterone deficiencies, ACTH deficiency is manifested by cortisol deficiency but not by aldosterone deficiency. Cortisol is necessary for efficent excretion of free water (20), and glucocorticoid deficiency is associated with retention of free water and development of hyponatraemia with a biochemical picture identical to SIADH. Patients with ACTH/cortisol deficiency and hyponatraemia have elevated plasma arginine vasopressin (AVP) concentrations, which further contribute to the tubular reabsorption of water (21). Glucocorticoid therapy has been shown to suppress AVP secretion (22), which allows the excretion of free water and the normalisation of plasma sodium concentrations in patients with ACTH deficiency (21). Diagnosis can be aided by the fact that patients with ACTH deficiency have a lower serum bicarbonate and aldosterone concentration than those with SIADH (23).

The distinction between true SIADH and the hyponatraemia associated with ACTH/cortisol deficiency is particularly important in patients with neurosurgical conditions, who commonly develop hyponatraemia (8). Over $50 \%$ of the patients with acute subarachnoid haemorrhage develop hyponatraemia, most of which has been attributed to SIADH (7). However, data have shown that a significant minority of long-term survivors of traumatic subarachnoid haemorrhage have evidence of permanent ACTH deficiency (24). The possibility that some of the hyponatraemia attributed in the immediate post-haemorrhage period to SIADH actually reflects acute ACTH deficiency remains unproven. However, $16 \%$ of the patients with acute traumatic brain injury develop ACTH deficiency (25), and some of these patients develop very severe hyponatraemia (26). We have adopted a policy of routine inclusion of measurement of cortisol at $0900 \mathrm{~h}$ in all patients with apparent SIADH due to neurosurgical conditions such as traumatic brain injury, subarachnoid haemorrhage, subdural haematoma and intracranial haemorrhage, and commencing empirical treatment with glucocorticoids if the reading is inappropriately low for the degree of expected stress-response $(<300 \mathrm{nmol} / \mathrm{l}$, and between 300 and $500 \mathrm{nmol} / \mathrm{l}$ if clinical suspicion is high). We have identified a significant number of patients with severe ACTH deficiency secondary to pituitary trauma as a result. Important clinical clues that neurosurgical patients with apparent SIADH may have acute ACTH deficiency include the presence of hypoglycaemia or hypotension, particularly when the latter is resistant to pressor agents.

SIADH is a clinical manifestation of a wide range of clinical disorders and drug therapies, and is the most common cause of euvolaemic hyponatraemia in modern clinical practice. A variety of clinical disorders can cause inappropriately increased AVP secretion, leading to inappropriate water retention and consequent hyponatraemia. The diagnostic criteria for SIADH are outlined in Table 2. Two supplementary criteria also exist - the direct measurement of a high AVP level and the measurement of urine excretion following administration of a water load. However, these are not often useful; RIAs with good enough antibodies to AVP to give meaningful results are not widely available, and the results take weeks to become available. The administration of a water load, which can worsen hyponatraemia significantly, should only be used in specialised units with experience of this investigation. The minimum information required for the diagnosis of SIADH is hyponatraemia in a euvolaemic patient with inappropriately concentrated urine, and the exclusion of hypothyroidism and glucocorticoid deficiency. Older literature sometimes states that urine osmolality must exceed plasma osmolality for the diagnosis to be confirmed, but this is fallacious. If plasma osmolality is subnormal (i.e. below the osmotic threshold for AVP secretion), then plasma AVP levels should be suppressed, which should then allow a hypotonic diuresis with maximally hypotonic urine $(<100 \mathrm{mosmol} / \mathrm{kg})$. Therefore, a urine osmolality of more than $100 \mathrm{mosmol} / \mathrm{kg}$ in a patient in whom AVP levels should be suppressed indicates that inappropriate antidiuresis is in progress and is consistent with the diagnosis of SIADH. Many patients are erroneously diagnosed with SIADH due to incomplete or inadequate implementation of the above criteria, and additional tests may prove useful. The lower

Table 2 Diagnostic criteria for the diagnosis of SIADH.

1. Hypo-osmolality; plasma osmolality $<280 \mathrm{mosmol} / \mathrm{kg}$, or plasma sodium concentration $<134 \mathrm{mmol} / \mathrm{l}$

2. Inappropriate urinary concentration (Uosm $>100 \mathrm{mosmol} / \mathrm{kg}$ ) for hyponatraemia

3. Patient is clinically euvolaemic

4. Elevated urinary sodium ( $>40 \mathrm{mmol} / \mathrm{l})$, with normal dietary salt and water intake

5. Exclusion of hypothyroidism, diuretics and glucocorticoid deficiency-particularly in patients with neurosurgical conditions 
fractional excretion of uric acid found in SIADH can be used to distinguish it from diuretic-induced hyponatraemia, as serum urea is a less reliable marker of hydration status in the elderly (27). As discussed earlier, when compared with patients with hyponatraemia due to hypocortisolaemia, patients with SIADH have normal serum bicarbonate and potassium, and a lower anion gap (28).

\section{Causes of SIADH}

The most common causes of SIADH are malignancy, pulmonary disorders, CNS disorders and medication; these are summarised in Table 3. SIADH was originally described by Bartter \& Schwartz in two patients with lung carcinoma, who had severe hyponatraemia at presentation (29). SIADH is quite common in patients with small cell carcinoma of the lung, and may be the presenting feature which instigates a search for the underlying tumour (30). Indeed, the link between

Table 3 Causes of SIADH.

\begin{tabular}{|c|c|}
\hline Malignancy & $\begin{array}{l}\text { Small cell lung cancer } \\
\text { Nasopharyngeal cancer } \\
\text { Mesothelioma } \\
\text { Gl tract malignancy } \\
\text { Pancreatic malignancy } \\
\text { GU tract malignancy } \\
\text { Lymphoma } \\
\text { Sarcoma }\end{array}$ \\
\hline Drugs & $\begin{array}{l}\text { Desmopressin } \\
\text { Selective serotonin reuptake } \\
\quad \text { inhibitors } \\
\text { Carbamazepine } \\
\text { Prostaglandins } \\
\text { Tricyclic antidepressants } \\
\text { Phenothiazines } \\
\text { Haloperidol } \\
\text { 3,4-Methylenedioxymethamphetamine } \\
\text { Quinolones } \\
\text { Leveteiracetam } \\
\text { Cyclophosphamide } \\
\text { Vincristine }\end{array}$ \\
\hline Pulmonary & $\begin{array}{l}\text { Pneumonia, especially Legionella and } \\
\quad \text { Mycoplasma } \\
\text { Tuberculosis } \\
\text { Abscess } \\
\text { Vasculitis } \\
\text { Positive pressure ventilation }\end{array}$ \\
\hline Intracranial pathology & $\begin{array}{l}\text { Tumour } \\
\text { Meningitis } \\
\text { Encephalitis } \\
\text { Abscess } \\
\text { Vasculitis } \\
\text { Subarachnoid haemorrhage } \\
\text { Subdural haemorrhage } \\
\text { Traumatic brain injury }\end{array}$ \\
\hline Miscellaneous & $\begin{array}{l}\text { Multiple sclerosis } \\
\text { Guillain-Barre syndrome } \\
\text { Acute intermittent porphyria } \\
\text { HIV } \\
\text { Idiopathic }\end{array}$ \\
\hline
\end{tabular}

malignant disease of various organs and SIADH is so strong that any patient presenting with SIADH and other suspicious symptoms such as weight loss should be thoroughly investigated for underlying malignancy.

The main pharmaceutical agents which have been implicated in the pathogenesis are the various groups of antidepressants; selective serotonin reuptake inhibitors (SSRIs) cause SIADH in between 0.5 and $32 \%$ of the patients, with hyponatraemia occurring most commonly in elderly female underweight patients who are also on diuretics (31). SIADH usually occurs in the first few weeks after SSRIs are introduced (32). Most drugs, including SSRIs, are thought to cause SIADH through stimulation of excess AVP secretion, although some may potentiate the effect of AVP at the level of the kidney. It has been estimated that $12 \%$ of the hospitalised patients on SSRI therapy develop SIADH (33). Many patients who are treated with these medications also have abnormally high thirst, which can give rise to very severe hyponatraemia when combined with SIADH. One important pharmaceutical cause of SIADH is 3,4-methylenedioxymethamphetamine (MDMA), which is an illegal recreational drug. The aetiology of MDMA-induced hyponatraemia is probably multifactorial, but it almost certainly causes inappropriate AVP secretion (34-36).

SIADH is also commonly associated with intracranial diseases, particularly traumatic brain injury $(25$, $37,38)$, where almost all cases resolve spontaneously with recovery from brain injury. Over $50 \%$ of the patients with subarachnoid haemorrhage develop hyponatraemia in the first week following the bleed, and $70 \%$ are due to SIADH (7). SIADH also commonly occurs after hypophysectomy and after surgery for primary brain tumours.

\section{Classification of SIADH}

SIADH occurs by definition when AVP secretion is not suppressed when plasma sodium concentration falls below the osmotic threshold for physiological AVP secretion (39). However, Zerbe et al. were able to utilise the measurement of plasma AVP with an early RIA to describe four different types of SIADH, defined by the pattern of AVP secretion across a range of plasma osmolalities (40) (Fig. 1):

i) Type $\mathrm{A}$ is the commonest form of SIADH. Some reports suggest that type A occurs in $40 \%$, though our own experience suggests that type $A$ is responsible for a much higher proportion of SIADH, at around 60-70\%. Characteristically, type A patients exhibit excessive, random secretion of AVP, with loss of the close linear relationship between plasma osmolality and plasma AVP. Type A is common in lung cancer; in vitro studies have demonstrated that some lung 


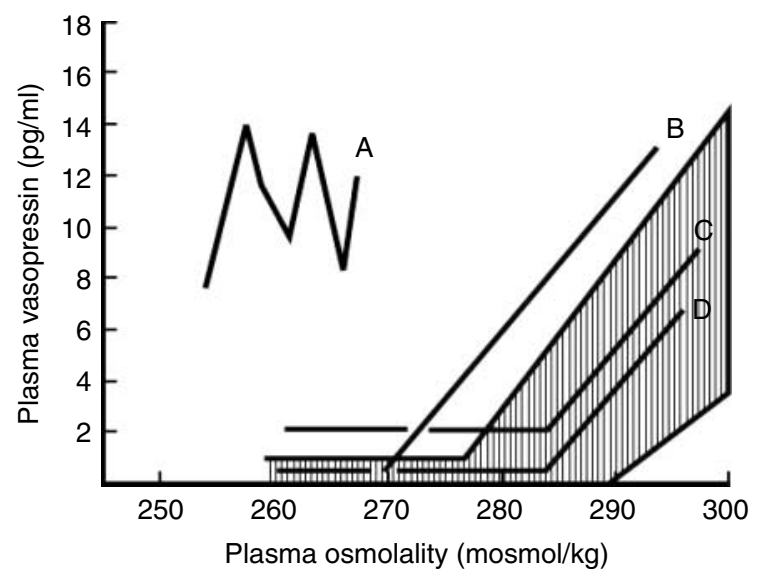

Figure 1 Summary of the four different patterns of AVP secretion in SIADH. Adapted with permission from Smith DM, McKenna K \& Thompson CJ. Hyponatraemia. Clinical Endocrinology 200052 $667-678$.

tumours synthesise AVP (41), and that tumour tissue stains positive for AVP mRNA (42). Plasma AVP concentrations in type A SIADH are not suppressed physiologically by drinking (43), which makes patients vulnerable to the development of severe hyponatraemia. Studies have also demonstrated a lower osmotic threshold for thirst appreciation in this type of SIADH (43). This type of SIADH is also characteristic of nasopharyngeal tumours, which also stain positive for AVP mRNA.

ii) Type B is also common (20-40\%). The osmotic threshold for AVP release is lowered - a 'reset osmostat' - such that secretion of AVP occurs at lower plasma osmolalities than normal. Because AVP is suppressed at plasma osmolalities below the lower, reset threshold, further overhydration leads to suppression of AVP release, which protects against the progression to severe hyponatraemia. Although most tumours manifest type A SIADH, some also present with type B SIADH, so the pattern of abnormal AVP secretion cannot be utilised to predict the causation of SIADH.

iii) Type $\mathrm{C}$ is a rare condition characterised by failure to suppress AVP secretion at plasma osmolalities below the osmotic threshold. Plasma AVP concentrations are thus inappropriately high at low plasma osmolalities, but there is a normal relationship between plasma osmolality and plasma AVP at physiological plasma osmolalities. This variant may be due to dysfunction of inhibitory neurones in the hypothalamus, leading to persistent low-grade basal AVP secretion (44).

iv) Type D is a rare clinical picture of SIADH with low or undetectable AVP levels and no detectable abnormality in circulating AVP response (45). It is thought that a nephrogenic SIADH (NSIAD) may be responsible for this picture (46). Gain-of-function mutations in the $\mathrm{V} 2$ receptor leading to a clinical picture of SIADH, with undetectable AVP levels, have been described. The identified mutations had different nucleotide substitutions causing different levels of $\mathrm{V} 2$ receptor activation (46). This syndrome appears to be inherited in an X-linked manner, although heterozygous females may have varying degrees of inappropriate antidiuresis. Owing to variable expressivity of the gene involved, NSIAD may be clinically undetectable for years, until other contributing factors in later life lead to clinically significant hyponatraemia (47).

Although patients with SIADH have ambient plasma osmolalities which are below the physiological osmotic threshold for thirst, they continue to drink apparently normal fluid volumes (36); the reason for this is unknown. The parallel lowering of the thresholds for thirst and AVP release ensures the maintenance of fluid intake, predisposing to persistent hyponatraemia. However, hyponatraemia is often limited by 'escape from antidiuresis'. This protective homeostatic mechanism occurs when the kidney begins to increase the clearance of free water despite inappropriate plasma AVP concentrations (48). Initial natriuresis is followed by an increase in urine flow (49) with consequent water loss; this allows plasma sodium to stabilise and, occasionally, to rise. Although plasma sodium concentration does not usually rise into the normal physiological range during escape from antidiuresis, the development of severe hyponatraemia is prevented.

Studies in rat models of SIADH have demonstrated that the increase in water reabsorption is secondary to AVP-mediated expression of renal aquaporin 2 (50). A decrease in aquaporin 2 protein expression and V2 receptor binding capacity $(51,52)$ is thought to cause the renal resistance to AVP observed during escape from antidiuresis. Normally, AVP has long-term effects on aquaporin 2 via mRNA and protein expression, but it also has short-term effects via the $\mathrm{V} 2$ receptor, leading to increased cAMP. It is likely that this short-term AVP action is also altered in escape, since reduced levels of cAMP in the collecting ducts of rats with escape from antidiuresis have been demonstrated (53). This finding of reduced cAMP activity suggests that the short-term regulation of aquaporin activity by reduced vesicle 'shuttling' is also important in the development of 'escape from antidiuresis'.

\section{Clinical consequences of hyponatraemia due to SIADH}

The symptoms associated with hyponatraemia are varied, and are generally related to the severity of hyponatraemia, the rate of change in plasma sodium concentration, and the osmotic gradient between intracellular and extracellular fluids. Patients with mild hyponatraemia (plasma sodium concentration 
$>130 \mathrm{mmol} / \mathrm{l}$ ) are traditionally regarded as asymptomatic, though the accompanying article in this supplementary issue of European Journal of Endocrinology will discuss data which challenge this assumption. At plasma sodium concentrations between 125 and $130 \mathrm{mmol} / \mathrm{l}$, anorexia, nausea, vomiting and abdominal pain may develop. As plasma sodium concentration falls to between 115 and $125 \mathrm{mmol} / \mathrm{l}$, agitation, confusion, hallucinations, incontinence and other neurological symptoms predominate. Hyponatraemia below $115 \mathrm{mmol} / \mathrm{l}$ may induce serious adverse neurological sequelae, such as seizures and coma, due to increased intracranial pressure. At this stage, hyponatraemia constitutes a medical emergency in need of urgent treatment. Although the main determinant of the symptoms experienced due to hyponatraemia is biochemical severity, symptoms are also more likely in the presence of other parameters, such as pyrexial illnesses, hypoxia and hypercapnia. If there is intracranial illness, space-occupying lesion or neurosurgical intervention, the onset of symptoms may occur at higher plasma sodium concentrations than usual.

The other main determinant of the onset or severity of symptoms is the rate of change in plasma sodium concentration. Symptoms are far more likely if the fall in plasma sodium is rapid, and tend to occur at higher plasma sodium concentrations. Chronic hyponatraemia may present as a relatively asymptomatic condition, even in cases where hyponatraemia is severe. In acute hyponatraemia, the main pathological consequence is the development of cerebral oedema, which may lead to raised intracranial pressure, cerebral herniation, hypoxia and even death (54). However, many patients with chronic hyponatraemia exhibit no apparent ill effects, despite severe biochemical hyponatraemia, due to the presence of cerebral adaptive mechanisms. The initial adaptive mechanism is the loss of intracerebral fluid, with depletion of sodium and potassium, to prevent cerebral oedema and gain of water (55). Later, glutamate, myo-inositol, $\mathrm{N}$-acetylaspartate, aspartate, creatine, taurine, $\gamma$-aminobutyric acid and phosphoethanolamine are lost from the brain, further decreasing intracerebral osmolality (56). This allows equilibration with the osmolality of the plasma, preventing the development of cerebral oedema.

However, although these adaptive mechanisms serve to protect against cerebral oedema, chronic hyponatraemia is not entirely benign (57), as adaptation seems to fail in some patients, especially in post-menopausal women. Indeed, in a Belgian study of 122 patients with mild chronic hyponatraemia $(126 \pm 5 \mathrm{mmol} / \mathrm{l})$, falls, gait disturbances and attention deficits were far more common in hyponatraemic patients versus matched controls (58). Also, recent data have shown that elderly patients with bone fractures are over four times as likely to be hyponatraemic as their peers (5). These clinical studies are supported by animal models of hyponatraemia, which show that chronic hyponatraemia induces severe bone loss in rats (59). Patients with chronic hyponatraemia not only are more prone to falls and fractures, but also are more likely to die when hospitalised for any cause (60); a study conducted in 2006 found that hyponatraemic hospital inpatients had a threefold higher mortality and a 25\% longer duration of hospital stay (9). These data have been replicated in a cohort of patients with subarachnoid haemorrhage.

\section{Conclusion}

Hyponatraemia is the commonest electrolyte imbalance in hospital inpatients, and it is associated with large and significant morbidity and mortality. SIADH is the most common cause of hyponatraemia in hospital inpatients; correct diagnosis requires accurate assessment of patients' volume status and the outruling of ACTH deficiency and hypothyroidism. The management of SIADH-induced euvolaemic hyponatraemia has traditionally been fluid restriction, but the emerging availability of the vasopressin receptor antagonist class of drugs offers clinicians the opportunity to induce an aquaresis in these patients and physiologically restore their serum sodium level.

\section{Declaration of interest}

Prof. Thompson is on the Otsuka advisory board for Tolvaptan. Dr Hannon has no conflicts of interest to declare. This paper forms part of a European Journal of Endocrinology supplement, supported by Otsuka Pharmaceutical Europe Ltd. The opinions or views expressed in this supplement are those of the authors, and do not necessarily reflect the opinions or recommendations of Otsuka Pharmaceutical Europe Ltd.

\section{Funding}

Prof. Thompson has received research funding from Novo Nordisk, Servier and Pfizer Pharmaceuticals.

\section{Author contribution statement}

All authors contributed to the preparation and submission of the manuscript.

\section{References}

1 Baran D \& Hutchinson TA. Outcome of hyponatraemia in a general hospital population. Clinical Nephrology 198422 72-76.

2 Gill GC \& Flear CTG. Hyponatraemia. Mechanisms and management. Lancet 19814 26-31.

3 Anderson RJ. Hospital acquired hyponatraemia. Kidney International $1986 \mathbf{2 9} 1237-1247$.

4 Sajadieh A, Binici Z, Mouridsen MR, Nielsen OW, Hansen JF \& Haugaard SB. Mild hyponatremia carries a poor prognosis in community subjects. American Journal of Medicine 2009122 $679-686$

5 Gankam Kengne F, Andres C, Sattar L, Melot C \& Decaux G. Mild hyponatremia and risk of fracture in the ambulatory elderly. Quarterly Journal of Medicine $2008 \mathbf{1 0 1} 583-588$. 
6 Zilberberg MD, Exuzides A, Spalding J, Foreman A, Jones AG, Colby C \& Shorr AF. Hyponatremia and hospital outcomes among patients with pneumonia: a retrospective cohort study. BMC Pulmonary Medicine 2008816.

7 Sherlock M, O'Sullivan E, Agha A, Behan LA, Rawluk D, Brennan P, Tormey W \& Thompson CJ. The incidence and pathophysiology of hyponatraemia after subarachnoid haemorrhage. Clinical Endocrinology 200664 250-254.

8 Sherlock M, O'Sullivan E, Agha A, Behan LA, Owens D, Finucane F, Rawluk D, Tormey W \& Thompson CJ. Incidence and pathophysiology of severe hyponatraemia in neurosurgical patients. Postgraduate Medical Journal 200985 171-175.

9 Gill G, Huda B, Boyd A, Skagen K, Wile D, Watson I \& van Heyningen $C$. Characteristics and mortality of severe hyponatraemia - a hospital-based study. Clinical Endocrinology $200665246-249$.

10 Clayton JA, Le Jeune IR \& Hall IP. Severe hyponatraemia in medical in-patients: aetiology, assessment and outcome. Quarterly Journal of Medicine 200699 505-511.

11 Hoorn EJ, Lindemans J \& Zietse R. Development of severe hyponatraemia in hospitalized patients: treatment-related risk factors and inadequate management. Nephrology, Dialysis, Transplantation 200621 70-76.

12 Stelfox HT, Ahmed SB, Khandwala F, Zygun D, Shahpori R \& Laupland K. The epidemiology of intensive care unit-acquired hyponatraemia and hypernatraemia in medical-surgical intensive care units. Critical Care 200812 R162.

13 Waikar SS, Mount DB \& Curhan GC. Mortality after hospitalization with mild, moderate, and severe hyponatremia. American Journal of Medicine 2009122 857-865.

14 Gill G \& Leese G. Hyponatraemia: biochemical and clinical perspectives. Postgraduate Medical Journal 199874 516-523.

15 Musch W \& Decaux G. Treating the syndrome of inappropriate ADH secretion with isotonic saline. Quarterly Journal of Medicine 199891 749-753.

16 Verbalis JG, Drutarosky MD, Ertel RJ \& Vollmer RR. Adaptive responses to sustained volume expansion in hyponatraemic rats. Journal of Endocrinology 1989122 421-431.

17 Hahn RG. Fluid absorption in endoscopic surgery. British Journal of Anaesthesia 200696 8-20.

18 Osborn DE, Rao PN, Greene MJ \& Barnard RJ. Fluid absorption during transurethral resection. BMJ 1980281 1549-1550.

19 Rosner MH. Exercise-associated hyponatraemia. Physician and Sportsmedicine 200836 55-61.

20 Green HH, Harrington AR \& Valtin H. On the role of antidiuretic hormone in the inhibition of acute water dieresis in adrenal insufficiency and the effects of gluco- and mineralocorticoids in reversing the inhibition. Journal of Clinical Investigation $1970 \mathbf{4 9}$ $1724-1736$.

21 Oelkers W. Hyponatremia and inappropriate secretion of vasopressin (antidiuretic hormone) in patients with hypopituitarism. New England Journal of Medicine 1989321 492-496.

22 Erkut ZA, Pool C \& Swaab DF. Glucocorticoids suppress corticotropin-releasing hormone and vasopressin expression in human hypothalamic neurons. Journal of Clinical Endocrinology and Metabolism 199883 2066-2073.

23 Decaux G, Musch W, Pennickx R \& Soupart A. Low plasma bicarbonate level in hyponatraemia related to adrenocorticotropin deficiency. Journal of Clinical Endocrinology and Metabolism 2003 88 5255-5257.

24 Aimaretti G, Ambrosio MR, Di Somma C, Gasperi M, Cannavò S, Scaroni C, Fusco A, Del Monte P, De Menis E, Faustini-Fustini M, Grimaldi F, Logoluso F, Razzore P, Rovere S, Benvenga S, Degli Uberti EC, De Marinis L, Lombardi G, Mantero F, Martino E, Giordano G \& Ghigo E. Residual pituitary function after brain injury-induced hypopituitarism: a prospective 12-month study. Journal of Clinical Endocrinology and Metabolism 200590 6085-6092.

25 Agha A, Rogers B, Mylotte D, Taleb F, Tormey W, Phillips J \& Thompson CJ. Neuroendocrine dysfunction in the acute phase of traumatic brain injury. Clinical Endocrinology $200460584-591$.
26 Agha A, Sherlock M \& Thompson CJ. Post-traumatic hyponatraemia due to acute hypopituitarism. Quarterly Journal of Medicine 200598 463-464.

27 Fenske W, Stork S, Koschker AC, Blechschmidt A, Lorenz D, Wortmann S \& Allolio B. Value of fractional uric acid excretion in differential diagnosis of hyponatraemic patients on diuretics. Journal of Clinical Endocrinology and Metabolism 200893 2991-2997.

28 Decaux G \& Musch W. Clinical laboratory evaluation of the syndrome of inappropriate secretion of antidiuretic hormone. Clinical Journal of the American Society of Nephrology 20083 $1175-1184$.

29 Schwartz WB, Bennett W, Curelop S \& Bartter FC. A syndrome of renal sodium loss and hyponatremia probably resulting from inappropriate secretion of antidiuretic hormone. American Journal of Medicine 195723 529-542.

30 Seute T, Leffers P, ten Velde GP \& Twijnstra A. Neurologic disorders in 432 consecutive patients with small cell lung carcinoma. Cancer $2004100801-806$.

31 Jacob S \& Spinler SA. Hyponatremia associated with selective serotonin-reuptake inhibitors in older adults. Annals of Pharmacotherapy 200640 1618-1622.

32 Miehle K, Paschke R \& Koch CA. Citalopram therapy as a risk factor for symptomatic hyponatremia caused by the syndrome of inappropriate secretion of antidiuretic hormone (SIADH): a case report. Pharmacopsychiatry 200538 181-182.

33 Bouman WP, Pinner G \& Johnson H. Incidence of selective serotonin reuptake inhibitor induced hyponatraemia due to the syndrome of inappropriate antidiuretic hormone secretion in the elderly. International Journal of Geriatric Psychiatry 199813 $123-125$.

34 Holden R \& Jackson MA. Near-fatal hyponatraemic coma due to vasopressin over-secretion after "ecstasy" (3,4-MDMA). Lancet 1996347105.

35 Gómez-Balaguer M, Peña H, Morillas C \& Hernández A. Syndrome of inappropriate antidiuretic hormone secretion and "designer drugs" (ecstasy). Journal of Pediatric Endocrinology and Metabolism 200013 437-438.

36 Ajaelo I, Koenig K \& Snoey E. Severe hyponatremia and inappropriate antidiuretic hormone secretion following ecstasy use. Academic Emergency Medicine 19985 839-840.

37 Agha A, Sherlock M, Phillips J, Tormey W \& Thompson CJ. The natural history of post-traumatic neurohypohysial dysfunction. European Journal of Endocrinology 2005152 371-377.

38 Agha A, Thornton E, O'Kelly P, Tormey W, Phillips J \& Thompson CJ. Posterior pituitary dysfunction following traumatic brain injury. Journal of Clinical Endocrinology and Metabolism 2004 89 5987-5992.

39 Thompson CJ, Bland J, Burd J \& Baylis PH. The osmotic thresholds for thirst and vasopressin release are similar in healthy man. Clinical Science $1986 \mathbf{7 1}$ 651-656.

40 Zerbe R, Stropes L \& Robertson G. Vasopressin function in the syndrome of inappropriate antidiuresis. Annual Review of Medicine 198031 315-327.

41 George JM, Capen CC \& Philips AS. Biosynthesis of vasopressin in vitro and ultrastructure of a bronchogenic cancer. Journal of Clinical Investigation $1972 \mathbf{5 1} 141-148$.

42 Gross AJ, Steinberg SM \& Reilly JG. Atrial natriuretic factor and arginine vasopressin production in tumor cell lines from patients with lung cancer and their relationship to serum sodium. Cancer Research 199353 67-74.

43 Smith D, Moore K, Tormey W, Baylis PH \& Thompson CJ. Downward resetting of the osmotic threshold for thirst in patients with SIADH. American Journal of Physiology. Endocrinology and Metabolism 2004287 E1019-E1023.

44 Robertson GL, Aycinema GL \& Zerbe RL. Neurogenic disorders of osmoregulation. American Journal of Medicine 198272 339-353.

45 Baylis PH. The syndrome of inappropriate antidiuretic hormone secretion. International Journal of Biochemistry and Cell Biology $2003351495-1499$. 
46 Feldman BJ, Rosenthal SM \& Vargas GA. Nephrogenic syndrome of inappropriate antidiuresis. New England Journal of Medicine 2005 352 1884-1890.

47 Decaux G, Vandergheynst F, Bouko Y, Parma J, Vassart G \& Vilain C. Nephrogenic syndrome of inappropriate antidiuresis in adults: high phenotypic variability in men and women from a large pedigree. Journal of the American Society of Nephrology 2007 18 606-612.

48 Verbalis JG, Murase T, Ecelbarger CA, Nielsen S \& Knepper MA. Studies of renal aquaporin-2 expression during renal escape from vasopressin-induced antidiuresis. Advances in Experimental Medicine and Biology 1998449 395-406.

49 Levinsky NG, Davidson DG \& Berliner RW. Changes in urine concentration during prolonged administration of vasopressin and water. American Journal of Physiology 1959196 451-456.

50 Ishikawa S, Saito T \& Kasono K. Pathological role of aquaporin-2 in impaired water excretion and hyponatremia. Journal of Neuroendocrinology 200416 293-296.

51 Ecelbarger CA, Nielsen S \& Olson BR. Role of renal aquaporins in escape from vasopressin-induced antidiuresis in rat. Journal of Clinical Investigation $1997991852-1863$.

52 Tian Y, Sandberg K, Murase T, Baker EA, Speth RC \& Verbalis JG. Vasopressin V2 receptor binding is down-regulated during renal escape from vasopressin-induced antidiuresis. Endocrinology 2000 141 307-314.

53 Ecelbarger CA, Chou CL, Lee AJ, DiGiovanni SR, Verbalis JG \& Knepper MA. Escape from vasopressin-induced antidiuresis: role of vasopressin resistance of the collecting duct. American Journal of Physiology 1998 274 F1161-F1166.
54 Verbalis JG. Adaptation to acute and chronic hyponatremia: implications for symptomatology, diagnosis, and therapy. Seminars in Nephrology 199818 3-19.

55 Rojiani AM, Prineas JW \& Cho ES. Electrolyte-induced demyelination in rats. 1. Role of the blood-brain barrier and edema. Acta Neuropathologica $1994 \mathbf{8 8} 287-292$.

56 Sterns RH, Baer J, Ebersol S, Thomas D, Lohr JW \& Kamm DE. Organic osmolytes in acute hyponatremia. American Journal of Physiology 1993 264 F833-F836.

57 Ayus JC \& Arieff AI. Chronic hyponatremic encephalopathy in postmenopausal women: association of therapies with morbidity and mortality. Journal of the American Medical Association 1999 281 2299-2304.

58 Renneboog B, Musch W, Vandemergel X, Manto MU \& Decaux G. Mild chronic hyponatremia is associated with falls, unsteadiness, and attention deficits. American Journal of Medicine 2006119 71e1-71e8.

59 Barsony J, Manigrasso M, Tam H, Sugimura Y, Tian Y \& Verbalis JG. Chronic hyponatraemia induces severe bone loss and mild hypogonadism in both male and female rats. ENDO09, Poster 1-167, 2009, June 10-13, Washington DC.

60 Anderson RJ, Chung HM, Kluge R \& Schrier RW. Hyponatremia: a prospective analysis of its epidemiology and the pathogenetic role of vasopressin. Annals of Internal Medicine 1985102 164-168.

Received 15 February 2010

Accepted 16 February 2010 